\title{
Nerve Abscesses in Leprosy in Northern India
}

\author{
V. N. SEHGAL, M.D. \\ Lecturer (Dermato-venereology) College of Medical Sciences, Banaras Hindu University, Varanasi, India
}

Reccntly the subject of nerve abscesses in leprosy has been reviewed by Sehgal and Gupta, emphasizing the rarity of the condition. Similar observations have however been made time and again by various workers like Lowe (1934), Mukherjee (1956), Gupta (1962), Wheate (1964) and Brown (1957, I965), from different parts of the world. No definite figures arc available from India, but it has been stated that in India; especially north (Int. J. Leprosy I 955), nerve abscesses are of relatively frequent occurrence. In the present paper two cases of nerve abscesses are reported from the area, where not many cascs have becn recorded.

\section{CASE HISTORIES}

CASE I

J. N., 30 years, male, attended the section of Dermatovenereology on 27 th October 1965 of S. S. Hospital, BHU, Varanasi, with a well defined erythematous patch situated on the ulnar side of the dorsum of the right hand, having impaired sensations. This, according to the patient, started about seven months prior to attending the hospital. on ExAmination: A well defined shiny erythematous patch was found on the dorsum of the right hand confined to the ulnar side. SENSATIONS: Temperature and touch were very much impaired. NERVES: Ulnar, median and radial nerves were thickened and tender. Clinically a diagnosis of luberculoid leprosy was made. The biopsy from the skin lesion was taken and studied histologically. The section revealed mild hyperkeratosis, with atrophy and thinning of the epidermis. The dermis showed focal collection of chronic inflammatory cells, more so around the adnexa of the skin (Fig. I). No acidfast bacilli could be demonstrated.

The patient was put on diamonodephenyl sulphone. While he was on treatment (after two months) he noticed a small swelling, a little above the elbow joint. This went on increasing progressively. During the period he also experienced weakness and wasting of the muscles of the right hand. on Examination: A swelling of the size of $\mathrm{I}_{2}^{\frac{1}{2}}$ " $\mathrm{x} \mathrm{I}^{\mathrm{I}}$ " was found, showing fluctuation and tenderness along the ulnar nerve, just above the elbow joint (Fig. 2). TREATMENT: A vertical incision of the size of two inches was made along the ulnar nerve in the elbow region. On complete exposure, a swelling of the size of $\mathrm{I}_{\frac{1}{2}}$ " $\mathrm{x} \mathrm{I}_{\mathrm{I}}$ " was seen along the thickened nerve (Fig. 3). An incision was made in the nerve sheath (Fig. 4). the pus drained out and the wound sutured. After the exposure and drainage the patient felt much better and constitutional symptoms lessened. Smears from purulent discharge showed degenerated polymorphonuclear leucocytes. No acid-fast bacilli could be demonstrated.

CASE 2

R. A., I 2 years, male was admitted to medical ward of S. S. Hospital with an anaesthetic patch on dorsum of the right foot of one year duration. The patient did not pay attention to it, till he noticed a progressively increasing painful swelling just above the patch. In the course of six months, he developed two more similar swellings along the sural nerve, and two along posterior tibial nerve. 'They were very painful. oN EXAmination: $\Lambda$ well clemarcated reddish, atrophic patch of the size of one inch diameter was seen. SENSATIONS: Temperature and touch were impaired over the patch. NERVES: Lateral popliteal, sural and posterior tibial were thickened. SWELlings: Five swellings were seen, which varied from half to one and a half inches in size. They were fluctuating and located three along the sural and two along the posterior tibial nerve. The clinical diagnosis of tuberculoid leprosy with multiple leprotic nerve abscesses was made. Histopathology of the skin lesion showed tuberculoid granulomata. Two of these abscesses were drained surgically to relieve the acute symptoms. Smears from the pus showed degenerated leucocytes. However no acid-fast bacilli could be seen.

\section{COMMENTS}

Two cases of leprotic nerve abscesses are reported, in which clinical features and biopsy studies showed the evidence of tuberculoid leprosy. It is believed that leprosy nerve abscesses occur more frequently in tuberculoid type. Development of nerve abscesses during its course shows high degree of immunity as mentioned by Dharmendra (1960). Better prognosis may therefore be expected in such patients. However, it is worth undertaking operative procedure, as attempted in the present cases, to relieve the acuteness of the symptoms and signs, because the severity of the 

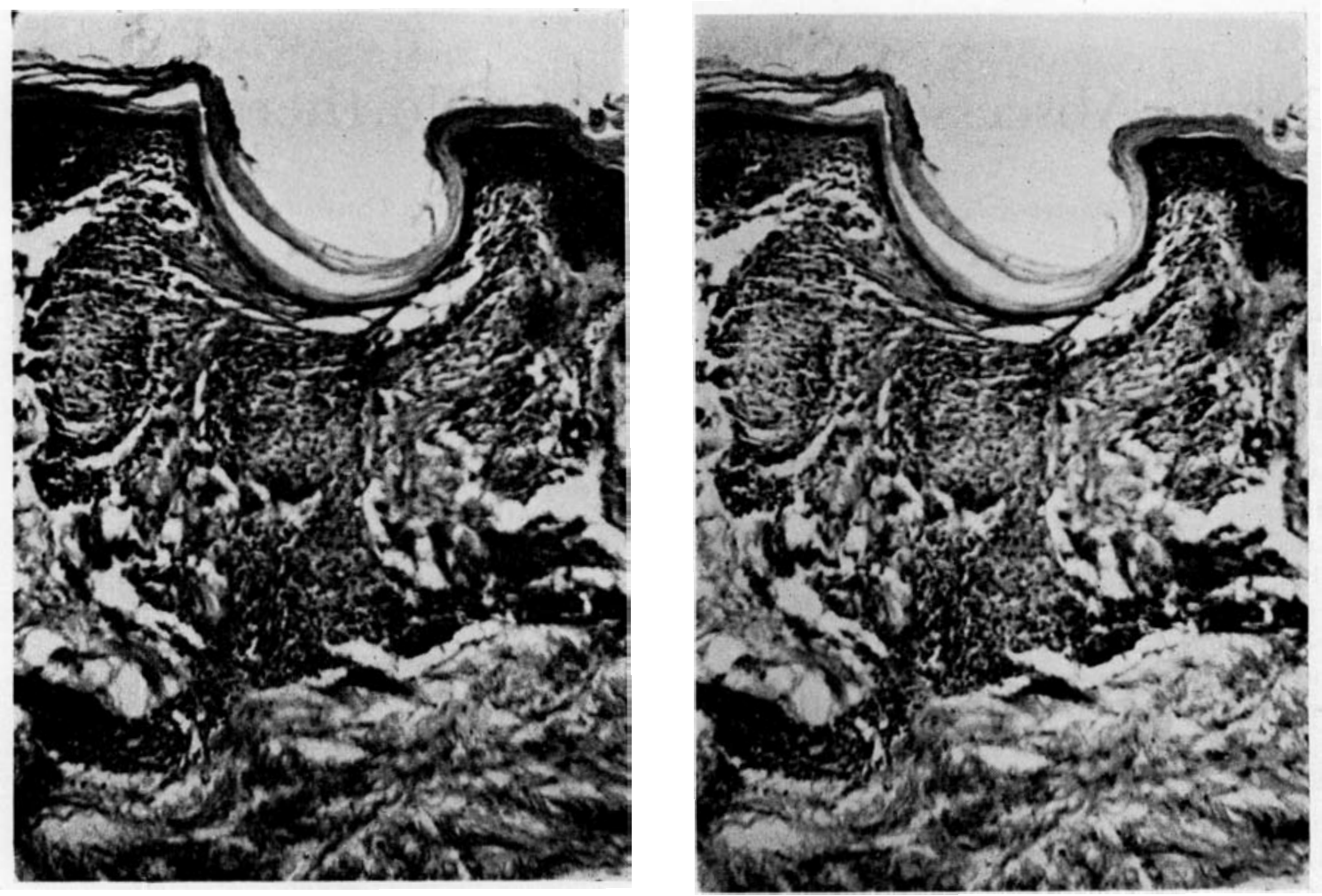

FIG. I. Skin Histology of nerve abscesses.
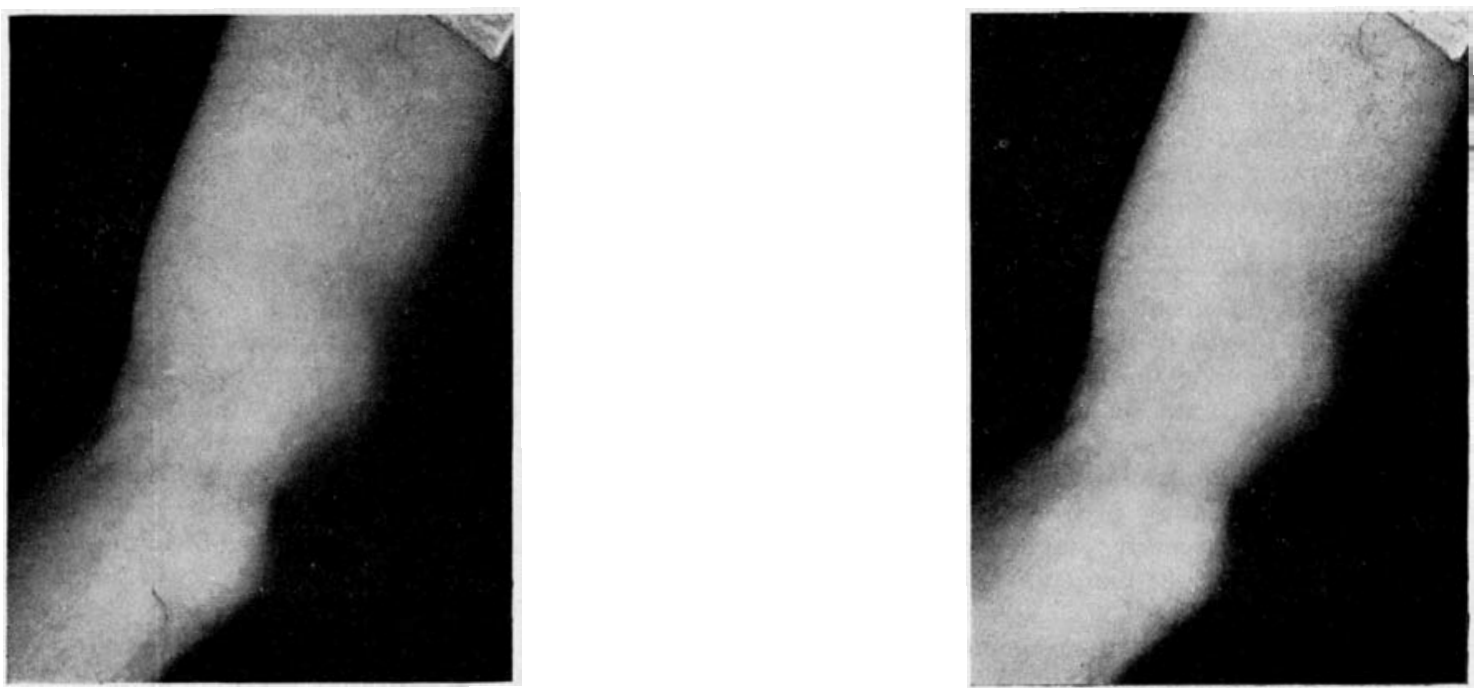

FIG. 2. Fluctuation with tenderness along the ulnar nerve. 

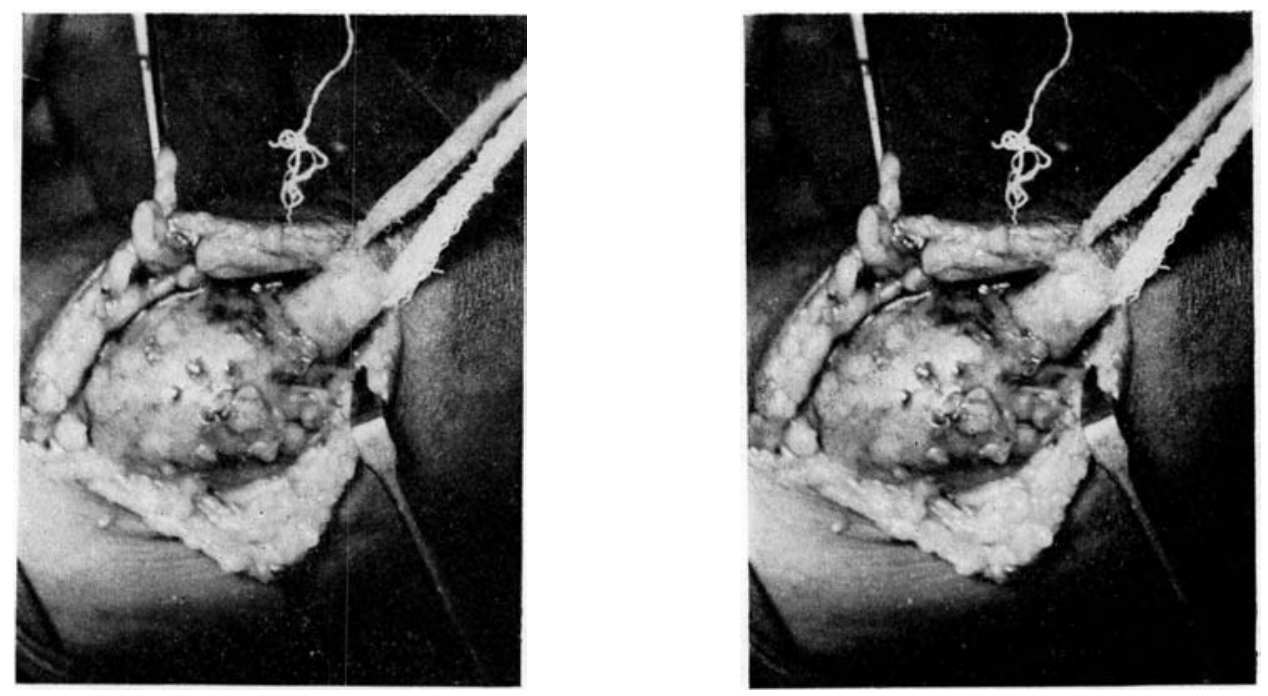

FIG. 3. Thickening of the nerve.
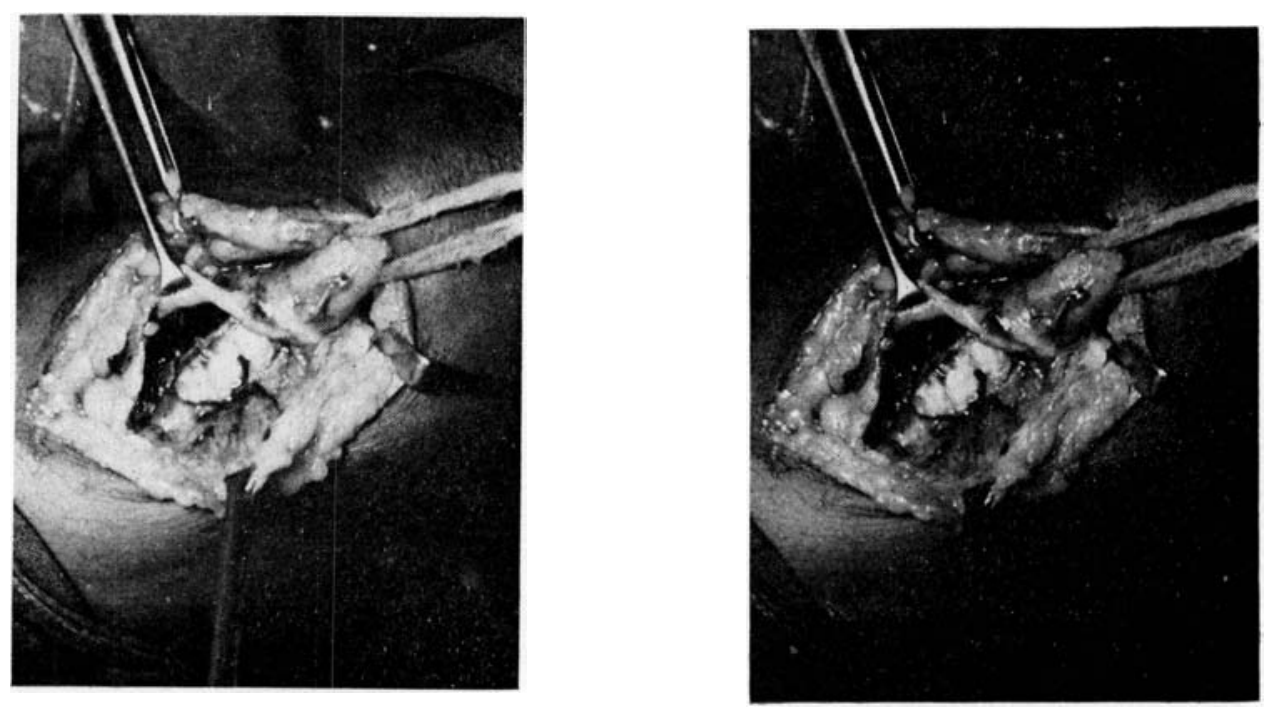

Fig. 4. Incision of nerve thickening. 
neural signs is in direct proportion to the pressure exerted by the pus on the nerve fibres.

SUMMAR Y

Clinical features and corroborative laboratory findings in cases of leprotic nerve abscesses arc described and their relatively infrequent occurrence is emphasized.

ACKNOWLEDGEMENTS

I gratefully appreciate Dr B. I'. L'crma, Lecturer, Orthopaedic Surgery, for carrying out the operative procedure, and Mr Grish Saxena for photography.

\section{REFERENCES}

BROWNe, s. G. ( I 957 ? : Leprosy Rev., 28, 20. Browne, s. G. (1965): Leprosy Rev. 36, 55 . DHARMEndra (ig6o): Notes on Leprosy, The Ministry of Health, Govt. of India, p 37.

EDITORIAL (i 955): Int. J. Leprosy, 23, 69. GUPTA, R. L. (1 962): Leprosy in India, 34, 205. LOWE, J. (I 934): Int. J. Leprosy, 2, 304. mukherjee, n., and ghosh, s. ^. (1956): J. Ind. Med. Assoc., 27, $29 \mathrm{I}$.

sehgal, v. N. and gupts, I. m.: Multiple Leprotic Nerve Abscesses in a Child (Under publication).

wheate, H. Iv. ( I964): Leprosy Rev., 35, 86. 